\title{
THE
}

\section{Understanding the genetics of chronic obstructive pulmonary disease, $\alpha 1$-antitrypsin deficiency, and implications for clinical practice}

Jennifer R. Mammen

University of Rhode Island, jmammen@uri.edu

Jung Eun Lee

University of Rhode Island, jelee@uri.edu

Follow this and additional works at: https://digitalcommons.uri.edu/nursing_facpubs

The University of Rhode Island Faculty have made this article openly available.

Please let us know how Open Access to this research benefits you.

This is a pre-publication author manuscript of the final, published article.

Terms of Use

This article is made available under the terms and conditions applicable towards Open Access Policy Articles, as set forth in our Terms of Use.

\section{Citation/Publisher Attribution}

Mammen, J. R. \& Lee, J. E. (2021) Understanding the genetics of COPD, $\alpha 1$-Antitrypsin Deficiency (AATD), and implications for clinical practice. Journal of the American Academy of Nurse Practitioners. 33(8) 576-579. doi: 10.1097/JXX.0000000000000627 Available at: http://dx.doi.org/10.1097/JXX.0000000000000627 
GENETICS OF COPD

Understanding the genetics of COPD, a1-Antitrypsin Deficiency (AATD), and implications for clinical practice

Authors: Jennifer R. Mammen, PhD NP-BC, ${ }^{1}$ Jung Eun Lee, PhD RN ${ }^{1}$

1. University of Rhode Island, College of Nursing, Kingston RI

Key words: COPD, $\alpha 1$-Antitrypsin Deficiency, genetics, epigenetics, phenotype

Corresponding Author:

Jennifer Mammen

jmammen@uri.edu

University of Rhode Island College of Nursing,

350 Eddy Street,

Providence RI

Word Counts Title: 13

Number of references: 16

Number of tables: 0

Number of figures: 0

Word count abstract: 134

Word count paper: 1665

\section{Author Contributions:}

Jennifer Mammen - drafting, revising

Jung Eun Lee - drafting, revising 


\section{GENETICS OF COPD}

Abstract

Cigarette smoking and poor air quality are the greatest risk factors for developing COPD,

3 but growing evidence indicates genetic factors also affect predisposition to and clinical

4 expression of disease. With the exception of $\alpha 1$-Antitrypsin deficiency (AATD), a rare

5 autosomal recessive disorder that is present in $1-3 \%$ of individuals with COPD, no single gene is

6 associated with the development of obstructive lung disease. Instead, a complex interplay of

7 genetic, epigenetic, and environmental factors are the basis for persistent inflammatory

8 responses, accelerated cell aging, cell death, and fibrosis, leading to the clinical symptoms of

9 COPD and different phenotypic presentations. In this brief review, we discuss current

10 understanding of the genetics of COPD, pathogenetics of AATD, epigenetic influences on

11 development of obstructive lung disease, and how classifying COPD by phenotype can influence

12 clinical treatment and patient outcomes. 


\section{GENETICS OF COPD}

\section{Genetics}

\section{Introduction}

Chronic obstructive pulmonary disease (COPD) affects approximately $6.4 \%$ of the U.S. adult population. It is the third leading cause of death worldwide, with estimated U.S. direct costs of 49 billion dollars annually (National Center for Health Statistics, 2016). Cigarette smoking and poor air quality are the greatest risk factors for COPD (GBD Chronic Respiratory Disease Collaborators, 2017), but there is growing evidence that genetic factors affect predisposition to and clinical expression of disease. Having a family history (FH) of COPD markedly increases an individual's risk of developing disease, especially in people who smoke. Compared to smokers without $\mathrm{FH}$ of COPD, smokers whose parents had COPD were three times as likely to develop disease, but non-smokers with FH of COPD had no increased risk compared to non-smokers without FH (Zhou et al., 2013). Thus, development of COPD is attributable to a combination of environmental and genetic factors.

With the exception of $\alpha 1$-Antitrypsin deficiency (AATD), which occurs in 1-3\% of patients with COPD, no single gene is associated with the development of obstructive lung disease (Sakornsakolpat et al., 2019). AATD is a rare disorder typically seen in people of European ancestry. Among people with AATD, Pulmonary disease occurs primarily as a result of abnormally shaped a1-Antitrypsin proteins (AAT) synthesized by the liver, rather than from environmental exposures. Normally, AAT protects lung tissue from being damaged by cytotoxic enzymes secreted by roaming neutrophils, a subset of white blood cells that act as firstresponders in non-specific immunity. However, in AATD, the abnormal proteins do not function correctly and are instead retained in the liver, causing cirrhosis and progressive lung damage through loss of neutrophil elastase inhibition (Strnad, McElvaney, \& Lomas, 2020). 


\section{GENETICS OF COPD}

Misfolded AAT proteins are created due to a single DNA point mutation (change in one

25 nucleotide base pair) at the allele SERPINA1, located on chromosome 14. An allele is a gene

26 pair, with one gene derived from each parent. AAT alleles can be homozygous (same genetic

27 sequence on chromosome 14) or heterozygous (different genetic sequences). These variations

28 are called protease inhibitor $\left(\mathrm{PI}^{*}\right)$ types, and are used to classify AATD. The unusual taxonomy

29 is based on nomenclature created prior to the identification of the SERPINA1 allele (Stoller,

30 Hupertz, \& Aboussouan, 2020).

$\mathrm{PI} * \mathrm{M}$ is the predominant (normal) AAT allele, whereas $\mathrm{PI} \mathrm{Z}^{\mathrm{Z}}$ is the most common

32 pathologic allele, followed by variants of PI*S, PI*I, and PI*F (Miravitlles et al., 2017).

33 Homozygous individuals without AATD would thus have the genotype PI*MM (i.e. two normal

34 PI*M genes). Because AATD is an autosomal recessive disorder, an individual must have two

35 abnormal genes to express disease. Therefore, an individual without clinical disease could also

36 have genotype $I^{*} \mathrm{MZ}$ or PI*MS (one normal and one disease allele). Similarly, an individual

37 with AATD could have genotype PI*ZZ, PI*ZS, or any other combination of two disease alleles.

38 AATD ranges from mild to severe, depending on the pathogenic variant of the PI* mutations.

39 For heterozygous individuals with one normal gene $(\mathrm{PI} * \mathrm{M})$, risk of developing obstructive lung

40 disease may still be elevated, even though clinical AATD is not present.

41 For the preceding reasons, in addition to usual COPD management, AATD should be

42 treated with intravenous infusion of plasma-purified AAT protein to promote correct immune

43 functioning and to slow the progression of emphysema (Miravitlles et al., 2017). Thus, while a

44 rare disorder, the Global Initiative for Chronic Obstructive Lung Disease (GOLD) guidelines

45 recommend that all individuals with COPD should be tested for AATD to facilitate identification 


\section{GENETICS OF COPD}

46 and proper treatment of affected individuals (Global Initiative for Chornic Obstructive Lung

47 Disease, 2021).

48 Like asthma and other complex diseases, COPD is otherwise genetically heterogenous,

49 with wide variability in genes, disease expression, progression, and subjective symptomatology

50 (Corlateanu et al., 2020). Prior to the advent of economical whole-genome sequencing, studies

51 in COPD genetics focused primarily on identifying discrete, shared DNA variations specific to

52 affected, related individuals (i.e. linkage studies). This was done by examining a series of

53 "candidate genes" thought to be related to COPD. However, linkage studies were unsuccessful

54 in finding any monogenic patterns of heredity, as occurs in other respiratory conditions like AAT

55 and cystic fibrosis.

56 With increasingly economical whole-genome sequencing, research into COPD genetics

57 transitioned from linkage studies to genome-wide association studies (GWAS), which enable the

58 examination of subtle variations in DNA across the entire genome, along with associations

59 between genetic patterns, clinical traits, and treatment responsiveness (Visscher et al., 2017).

60 Researchers using this approach have identified 156 different genes at 82 significant loci, of

61 which $>15 \%$ overlap with asthma and pulmonary fibrosis (Sakornsakolpat et al., 2019).

The importance of genetics for COPD lies in the fact that inflammatory responses, which

63 modulate disease progression and clinical presentation, are driven by DNA. Genetic code

64 defines how and when inflammatory mediators are created, and how noxious stimuli (e.g.

65 particulates) are perceived and processed. Cigarette smoking, the primary cause of COPD,

66 exposes lung tissue to elevated levels of reactive oxygen species (ROS). Excess ROS damages

67 DNA and leads to increased expression of genes that control inflammation through altered

68 activity of intracellular mediators, most commonly Nuclear factor E2-related factor (Nrf2). Nrf2 


\section{GENETICS OF COPD}

69 regulates hundreds of genes downstream, and is central to cellular management of oxidative

70 stress and inflammation. With dysregulation of $N r f 2$, cellular stress and aging are greatly

71 accelerated. These intracellular changes cause the release of pro-inflammatory mediators into

72 the extracellular space. Chemical messengers then attract other inflammation-regulating cells

73 (e.g. macrophages, neutrophils, T-helper cells), which precipitate the release of additional

74 cytotoxic chemokines and cytokines (commonly interleukins), further damaging surrounding

75 tissues. Cumulatively, these processes form a reinforcing cycle of damage, inflammation,

76 accelerated cell death, and fibrosis (Hikichi, Mizumura, Maruoka, \& Gon, 2019). It is also worth

77 noting that like asthma, inflammation in COPD can be mediated by different T-helper (Th)

78 pathways. Inflammation in COPD typically follows $T h 1$ and $T h 17$ pathways (also known as

79 Type 1 non-allergic airway inflammation), but may also be mediated by Th2 pathways. This has

80 been referred to as Type 2 (allergic) airway inflammation or Type 2 COPD (Oishi, Matsunaga,

81 Shirai, Hirai, \& Gon, 2020). It has been suggested that the inflammatory mechanism via

82 different T-helper pathways may underlie variable responsiveness to treatments; Th2 pathways

83 are susceptible to use of inhaled corticosteroids (ICS), whereas Th1 and Th17 pathways have

84 poor ICS-responsiveness.

85 Epigenetics

86 Early stage evidence indicates that epigenetic influences also play an important role in

87 COPD development through a secondary process called DNA methylation (He, Tang, Huang, \&

88 Li, 2020). Methylation occurs when a histone molecule becomes entangled with a portion of

89 DNA, blocking translation and effectively "silencing" that section of genetic code. (This can be

90 conceptualized as bubble gum tangled in a strand of hair.) Methylation is actually a normal

91 process and acts as an essential on/off switch for gene expression during growth and 


\section{GENETICS OF COPD}

92 development. However, abnormal methylation causes increased down-regulation of protective

93 genes, contributing to accelerated cellular aging and death (Du et al., 2019). Furthermore,

94 evidence indicates that prenatal smoke exposure might also increase risk for later developing

95 COPD through epigenetic mechanisms, as hyper-methylated DNA has been observed in the cord

96 blood of infants exposed to cigarette smoke in utero (Krauss-Etschmann, Meyer, Dehmel, \&

97 Hylkema, 2015). This suggests that exposure to environmental toxins could have prolonged

98 epigenetic effects contributing to development of disease. Because methylation is reversible, it

99 is hypothetically amenable to targeted drug therapy, and is therefore an area of active

100 pharmaceutical research.

\section{Clinical Phenotypes}

102 Consistent with the complex underlying genetics, clinical presentation of COPD is also

103 highly variable. Once treated as a single entity, COPD is now considered to be an umbrella term

104 with several distinct phenotypes (Sakornsakolpat et al., 2019). Phenotypes are essentially sub-

105 groups within COPD that have shared clinical characteristics of obstructive lung disease, but also

106 have clinically important between-group differences, such as who is typically affected, patterns

107 of symptoms and disease progression, and variable responsiveness to treatments. Classifying

108 and treating COPD by phenotype can help to predict outcomes and improve clinical

109 management.

110 The first phenotypic classification system for COPD was proposed in 1989, and included

111 chronic bronchitis, emphysema, and asthma (Snider, 1989). Since then, multiple taxonomies

112 have been proposed, with currently accepted phenotypes including AATD, chronic bronchitis,

113 emphysema, frequent exacerbator and rare exacerbator (Corlateanu et al., 2020). Asthma and

114 COPD are now considered fully-distinct diseases entities, albeit sharing common characteristics, 


\section{GENETICS OF COPD}

115 and the use of "Asthma-COPD overlap" is no longer encouraged (Global Initiative for Chornic

116 Obstructive Lung Disease, 2021). Emerging evidence points to additional phenotypic variations

117 that may include a "no smoking COPD" group or overlap with other co-morbidities such as

118 bronchiectasis.

\section{Implications for Practice}

120 Since 2011, GOLD guidelines for pharmacologic management of COPD have capitalized

121 on four broad phenotypic groupings to determine the most appropriate first line therapy, based

122 on responsiveness to treatment (Global Initiative for Chornic Obstructive Lung Disease, 2021).

123 These phenotypes (GOLD Group A, B, C, D) are clustered by two clinical characteristics: risk of

124 exacerbation with or without hospitalization (low risk/high risk) versus overall symptom burden

125 (low symptoms/high symptoms). While spirometric classification is assessed (grade of FEV1\%

126 predicted), it is not used as a sole factor in treatment selection, as there is no evidence to support

127 efficacy. Serum eosinophil counts $(>100-300$ cell $/ \mu \mathrm{L})$ can be predictive of ICS responsiveness

128 and Type 2 airway inflammation, and can help to determine if inhaled or oral corticosteroids

129 could be beneficial. At present, biomarkers, genomic, and pharmacogenetic testing are not

130 recommended for clinical management, with the exception of AATD testing, which should be

131 performed once for all patients with COPD (ICD-10-CM code E88.01). If not covered by

132 insurance, free confidential DNA test kits are available to providers or patients directly (Alpha-1

133 Foundation, n.d.). Similarly, most contemporary direct-to-consumer genetic testing services can

134 identify SERPINA1 variants (Hersh, Campbell, Scott, \& Raby, 2019; Horton et al., 2019). 


\section{GENETICS OF COPD}

137 In conclusion, COPD is a common, preventable inflammatory disease that occurs due to a

138 complex interplay of genetic and environmental factors. Current understanding of COPD

139 supports use of broad phenotypic categories to inform clinical management and predict

140 outcomes. Increased understanding of genetic and epigenetic factors will likely result in

141 increasingly targeted treatment options over time.

142

143 


\section{GENETICS OF COPD}

\section{References}

146
Alpha-1 Foundation. (n.d.). Testing for Alpha-1 Antitripsin Disorder. Retrieved from https://www.alpha1.org/newly-diagnosed/learning-about-alpha-1/testing-for-alpha-1/

Corlateanu, A., Mendez, Y., Wang, Y., Garnica, R. J. A., Botnaru, V., \& Siafakas, N. (2020). "Chronic obstructive pulmonary disease and phenotypes: a state-of-the-art.". Pulmonology, 26(2), 95-100. doi:10.1016/j.pulmoe.2019.10.006

Du, X., Yuan, L., Wu, M., Men, M., He, R., Wang, L., . . . Liu, C. (2019). Variable DNA methylation of aging-related genes is associated with male COPD. Respiratory Research, 20(1), 243. doi:10.1186/s12931-019-1215-7

GBD Chronic Respiratory Disease Collaborators. (2017). Global, regional, and national deaths, prevalence, disability-adjusted life years, and years lived with disability for chronic obstructive pulmonary disease and asthma, 1990-2015: a systematic analysis for the Global Burden of Disease Study 2015. Lancet Respiratory Medicine, 5(9), 691-706. doi:10.1016/S2213-2600(17)30293-X

Global Initiative for Chornic Obstructive Lung Disease. (2021). Pocket guide to COPD diagnosis, management, and prevention. Retrieved from https://goldcopd.org/wpcontent/uploads/2020/12/GOLD-2021-POCKET-GUIDE-v2.0-14Dec20_WMV.pdf

He, L. X., Tang, Z. H., Huang, Q. S., \& Li, W. H. (2020). DNA Methylation: A Potential Biomarker of Chronic Obstructive Pulmonary Disease. Frontiers of Cell Development \& Biology, 8, 585. doi:10.3389/fcell.2020.00585

Hersh, C. P., Campbell, E. J., Scott, L. R., \& Raby, B. A. (2019). Alpha-1 Antitrypsin Deficiency as an Incidental Finding in Clinical Genetic Testing. American Journal of Respiratory and Critical Care Medicine, 199(2), 246-248. doi:10.1164/rccm.201809-1679LE

Hikichi, M., Mizumura, K., Maruoka, S., \& Gon, Y. (2019). Pathogenesis of chronic obstructive pulmonary disease (COPD) induced by cigarette smoke. Journal of Thoracic Diseases, 11(Suppl 17), S2129-S2140. doi:10.21037/jtd.2019.10.43

Horton, R., Crawford, G., Freeman, L., Fenwick, A., Wright, C. F., \& Lucassen, A. (2019). Direct-to-consumer genetic testing. BMJ, 367, 15688. doi:10.1136/bmj.15688

Krauss-Etschmann, S., Meyer, K. F., Dehmel, S., \& Hylkema, M. N. (2015). Inter- and transgenerational epigenetic inheritance: evidence in asthma and COPD? Clinical Epigenetics, 7, 53. doi:10.1186/s13148-015-0085-1

Miravitlles, M., Dirksen, A., Ferrarotti, I., Koblizek, V., Lange, P., Mahadeva, R., .. . Stockley, R. A. (2017). European Respiratory Society statement: diagnosis and treatment of pulmonary disease in alphal-antitrypsin deficiency. European Respiratory Journal, 50(5). doi:10.1183/13993003.00610-2017

National Center for Health Statistics. (2016). Health, United States 2015 with Special Feature on Racial and Ethnic Health Disparities. Hyattsville, MD Retrieved from https:/pubmed.ncbi.nlm.nih.gov/27308685/

Oishi, K., Matsunaga, K., Shirai, T., Hirai, K., \& Gon, Y. (2020). Role of Type2 Inflammatory Biomarkers in Chronic Obstructive Pulmonary Disease. Journal of Clinical Medicine, 9(8). doi:10.3390/jcm9082670

Sakornsakolpat, P., Prokopenko, D., Lamontagne, M., Reeve, N. F., Guyatt, A. L., Jackson, V. E., . . International, C. G. C. (2019). Genetic landscape of chronic obstructive 


\section{GENETICS OF COPD}

pulmonary disease identifies heterogeneous cell-type and phenotype associations. Nature Genetics, 51(3), 494-505. doi:10.1038/s41588-018-0342-2

Snider, G. L. (1989). Chronic obstructive pulmonary disease: a definition and implications of structural determinants of airflow obstruction for epidemiology. American Review of Respiratory Diseases, 140 (3 Pt 2), S3-8. doi:10.1164/ajrccm/140.3_Pt_2.S3

Stoller, J., Hupertz, V., \& Aboussouan, L. (2020). Alpha-1 Antitrypsin Deficiency. [1993-2021]. In M. Adam, H. Ardinger, \& R. Pagon (Eds.), GeneReviews ${ }^{\circledR}$ [Internet]. . Retrieved from https://www.ncbi.nlm.nih.gov/books/NBK1519/

Strnad, P., McElvaney, N. G., \& Lomas, D. A. (2020). Alpha1-Antitrypsin Deficiency. New England Journal of Medicine, 382(15), 1443-1455. doi:10.1056/NEJMra1910234

Visscher, P. M., Wray, N. R., Zhang, Q., Sklar, P., McCarthy, M. I., Brown, M. A., \& Yang, J. (2017). 10 Years of GWAS Discovery: Biology, Function, and Translation. American Journal of Human Genetics, 101(1), 5-22. doi:10.1016/j.ajhg.2017.06.005

Zhou, J. J., Cho, M. H., Castaldi, P. J., Hersh, C. P., Silverman, E. K., \& Laird, N. M. (2013). Heritability of chronic obstructive pulmonary disease and related phenotypes in smokers. American Journal of Respiratory and Critical Care Medicine, 188(8), 941-947. doi:10.1164/rcem.201302-0263OC 